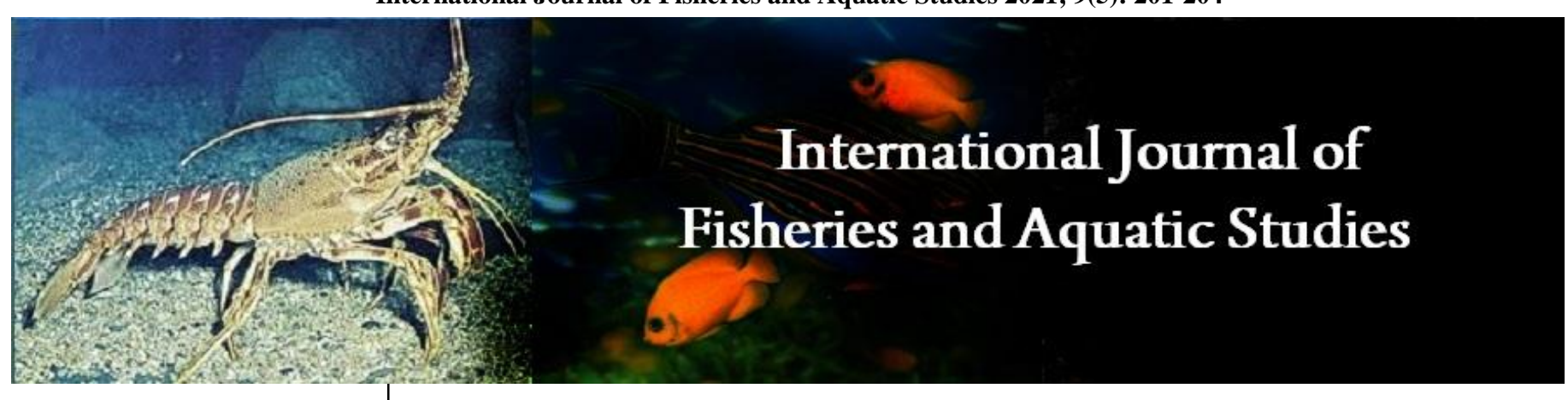

E-ISSN: 2347-5129

P-ISSN: 2394-0506

(ICV-Poland) Impact Value: 5.62

(GIF) Impact Factor: 0.549

IJFAS 2021; 9(5): 201-204

(C) 2021 IJFAS

www.fisheriesjournal.com

Received: 01-07-2021

Accepted: 03-08-2021

Madhav Bhilave

Division of Fisheries Science,

Department of Zoology,

Shivaji University, Kolhapur,

Maharashtra, India

Corresponding Author:

Madhav Bhilave

Division of Fisheries Science,

Department of Zoology,

Shivaji University, Kolhapur,

Maharashtra, India

\section{Effect of methanol on lipid profile of freshwater fish Cirrhinus mrigala}

\section{Madhav Bhilave}

DOI: https://doi.org/10.22271/fish.2021.v9.i5c.2569

\begin{abstract}
Toxicology is a discipline, overlapping with biology, chemistry, pharmacology, and medicine, that involves the study of the adverse effects of chemical substances on living organisms and the practice of diagnosing and treating exposures to toxins and toxicants. The relationship between dose and its effects on the exposed organism is of high significance in toxicology. Factors that influence toxicity includes the dosage, route of exposure, species, age, sex, and environment. Toxicologists are experts on poisons and poisoning. Most chemicals display a classic dose response curve at a low dose (below a threshold), no effect is observed. Some show a phenomenon known as sufficient challenge - a small exposure produces animals that "grow more rapidly, have better general appearance and coat quality, have fewer tumors, and live longer than the control animals". Aquatic Pollution produced by the large amounts of waste material modifies the water in a negative manner. Such type of ecological changes occurs when harmful pollutants like heavy metals, pesticides, phenols and radioactive waste are directly or indirectly discharged into the aquatic ecosystems via industrial and urban effluents.

In the present study Methanol was selected as Toxicant on fingerlings of freshwater fish Cirrhinus mrigala to understand the changes in lipid profile after acute exposure. It was observed that lipid profile decreased as the dose component was increased.
\end{abstract}

Keywords: toxicant, methanol, freshwater fish

\section{Introduction}

Aquatic toxicology is the part of science which incorporates investigation of the impacts created by substance on sea-going life forms at different levels of association in biological systems. Sea-going toxicology is an interdisciplinary field which includes oceanic biology, toxicology and amphibian science. The field of sea-going toxicological investigation incorporates freshwater, marine water and residue conditions. Harmfulness test incorporates intense poisonous quality tests (24-96 hours) and perpetual lethality test (at least 7 days). The Acute poisonous quality test incorporates antagonistic impacts of compound to a living being amid here and now presentation and ceaseless danger has a capacity of a substance to create destructive impacts over a long haul period. Numerous methodologies have been concentrated to assess the intense and endless toxicological impacts of contaminations in crisp water biological communities. Lethality tests not just exhibits that a compound is protected or not, but rather likewise portrays the impacts, a synthetic can create or not. The motivation behind these tests is to dole out far reaching data in hazard assessment.

Methanol is an industrial chemical used after 1800s. It is a toxic. This chemical are used to produce biodiesel and also used in ethanol manufacturing industries as a denaturant additive. In the 2010, the American Methanol Institute (AMI) evaluation stated the methanol demand may be reach up to the 882 million gallons per year. Production of Methanol increases to fulfill the expected future demand. For fulfillment of the need of methanol, transportation, storage and distribution facility has to be increased. With increasing production, transportation and storage of methanol, the chances for accidental releases to the environment will also increase. The fates of methanol on the environment and its effect on aquatic organisms have not been studied. Methanol, the substance chose for present examination, is a dismal, fluid and combustible compound with the equation $\mathrm{CH}_{3} \mathrm{OH}$ utilized as a mechanical concoction after 1800s. It is a lethal compound utilized as a dissolvable, radiator fluid and fuel. 
Methanol is incorporated from the damaging refining of wood and furthermore from carbon monoxide and hydrogen. Methanol is harmful, when $10 \mathrm{ml}$ of the substance is devoured incidentally by drinking, it cause visual deficiency and $100 \mathrm{ml}$ results in the passing of a person. These synthetic concoctions are utilized to create biodiesel, and utilized in ethanol fabricating ventures as a denaturant added substance.

Generation of Methanol is expanded to satisfy the normal future interest of fuel. In United States, 17 plants are associated with methanol generation, which delivers around 2.25billion gallons of methanol for every year. In 1993, around 12 million gallons of methanol were utilized as an immediate fuel and 212 million gallons were utilized in different energizes and fuel added substances in the California. In 2010, the American Methanol Institute (AMI) assessment expressed the methanol request may reach up to 882 million gallons for every year. To conquer any hindrance, more Methanol's' is delivered, which thusly builds transportation, stockpiling and appropriation offices. With increment in the creation, transportation and capacity of methanol, the odds of inadvertent discharges into nature will likewise increment. In Annual Toxics Release Inventory (1992) it is noticed that, 'out of the all detailed substance, methanol have third rank in synthetic which is discharged by industry to the earth.

\section{Materials and Methods}

Biochemical adjustments are eluded as bioindicator for checking the obsessive and physiological status of fish (Baskaran 1991) [2]. Any adjustments in biochemical parameters speak to the reaction of organ frameworks to toxicants by changing their capacity (Verma and Tonk, 1983) [9]. Analytical grade Methanol $\left(\mathrm{CH}_{3} \mathrm{OH}\right.$, Ranbaxy, India; molecular weight 32.04 ; weight per milliliter at $20^{\circ} \mathrm{C}$ is 0.790 - $0.793 \mathrm{~g}$ ) was used as the test chemical. It is available in liquid form and was treated directly to the test medium. Required volume of the chemical was added to the test medium.

The live fingerlings of freshwater fish Cirrhinus mrigala, weighing about 8 to $10 \mathrm{~g}$ and 10 to $12 \mathrm{~cm}$ in length, were collected from Government fish seed production centre, Dhom, Tal -Wai, Dist- Satara. After acclimatization they were transported to the laboratory and kept in the glass aquaria containing aerated water. Fishes were given $0.05 \% \mathrm{KMnO}_{4}$ treatment (bath treatment) for 4 to 5 minutes to prevent dermal and other biotic infections. They were fed twice a day with groundnut oil cake at the rate of $2 \%$ of body weight; water in aquarium was changed after every 24 hours to maintain a healthy environment for the fish.

Estimation of Lipid (Barnes and Black stock, 1973) ${ }^{[1]}$

Total lipid content was estimated by Barnes and Black Stock (1973) ${ }^{[1]}$ method. For this experiment, $50 \mathrm{mg}$ of tissue was homogenized in $10 \mathrm{ml}$ Flosch's mixture (Chloroform and Methanol in the ratio 2:1). Prepared homogenate was filtered into the test tube through Whatman filter paper. Filtrate solvent was evaporated at $40^{\circ} \mathrm{C}$ in water bath for $2 \mathrm{hrs}$ and then $1 \mathrm{ml}$ of conc. $\mathrm{H}_{2} \mathrm{SO}_{4}$ was added in it; mixed well and mixture was heated for 10 minutes in boiling water bath. After cooling, $2 \mathrm{ml}$ of vanillin reagent was added mixed well and was allowed to stand for half an hour. Pink color was developed. The optical density was measured at $530 \mathrm{~nm}$ with the help of UV-1800 spectrophotometer against the blank. Standard was prepared by taking $0.2 \mathrm{ml}$ of standard cholesterol with $5 \mathrm{ml}$ of vanillin reagent. Blank was prepared by mixing $0.2 \mathrm{ml}$ of chloroform with $5 \mathrm{ml}$ of vanillin reagent.

\section{Result}

Acute toxicity study of Methanol to Cirrhinus mrigala

On exposure of freshwater fish Cirrhinus mrigala to Methanol, there was $10 \%$ mortality at $10.5 \mathrm{ml} / 1$ after 96 hours. As the concentration of toxicant was increased; there was increase in the percent mortality of the fish. There was $20 \%$ mortality at $11 \mathrm{ml} / 1$, after 96 hours, whereas at $11.5,12,12.5$, $13,13.5,14,14.5$ and $15 \mathrm{ml} / 1$ there was $30 \%, 40 \%, 50 \%, 60 \%$, $70 \%, 80 \%, 90 \%$ and $100 \%$ mortality respectively at the end of 96 hours (Table 2). The regression equation between $\log$ concentrations (in ppm) (X) and the probit mortality (Y) was calculated statistically for acute toxicity using the formula $\mathrm{Y}=$ $\alpha+\beta \log X$ and $95 \%$ fiducial limits was also calculated. The observed $\mathrm{LC}_{0}$ and $\mathrm{LC}_{50}$ values are $10 \mathrm{ml} / \mathrm{l}$ and $12.5 \mathrm{ml} / \mathrm{l}$ respectively.

\section{Total lipid content Acute exposure}

The calculated values for total lipid content and percent changes with standard deviation over control after acute exposure to Methanol are given in Table and are graphically represented in Figure.

\section{Control group}

In the control fish, Cirrhinus mrigala the total lipid content was in the order of: Muscle > Liver > Gill > Brain.

\section{Experimental group}

Cirrhinus mrigala exposed to lethal concentrations of Methanol showed significant decrease in lipid content compared with control. After acute exposure to two different concentrations of Methanol $\mathrm{LC}_{0}$ and $\mathrm{LC}_{50}$, percent change of total lipid content, depletes in the order of Liver > Brain > Muscle $>$ Gill and Liver $>$ Muscle $>$ Brain $>$ Gill respectively. The total lipid content ranges within $2.57>1.76$ in Liver, 2.82 $>2.14$ in Muscle, $2.14>0.77$ in Brain and $1.353>1.12$ in Gill. In $\mathrm{LC}_{0}$ group, percent depletion was significant $(P<0.05)$ in Liver (-19.84) followed by Brain (-14.43), Muscle (-14.32) and Gill (-14.07). In $\mathrm{LC}_{50}$ group of Methanol, there was moderate $(P<0.01)$ percent depletion was observed in Liver $(-$ $31.25)$ and Muscle $(-24.11)$ while significant $(P<0.05)$ depletion observed in Brain (-20.62) and Gill (-17.04).

The maximum percent change of total lipid depletion observed in Liver $(-19.84 \%)$ in $\mathrm{LC}_{0}$ group and $(-31.25 \%)$ in $\mathrm{LC}_{50}$ group and minimum percentage was observed in Gill as $(-14.07 \%)$ in $\mathrm{LC}_{0}$ group and $(-17.04 \%)$ in $\mathrm{LC}_{50}$ group when compared with the control.

Table 1: Effect of Methanol on the total Lipid content in various organs of the fish Cirrhinus mrigala after acute exposure (Mg/100mg wet wt of tissue)

\begin{tabular}{|c|c|c|c|c|}
\hline \multirow{2}{*}{ Sr. No. } & \multirow{2}{*}{ Organs } & \multirow{2}{*}{ Control } & \multicolumn{2}{|c|}{ Exposure of Methanol } \\
\cline { 3 - 5 } & & $1.353 \pm 0.12$ & LC $_{\mathbf{0}}$ & LC $_{\mathbf{5 0}}$ \\
\hline 1. & Gill & $2.57 \pm 0.29$ & $2.06 \pm 0.09^{*}(-14.07)$ & $1.12 \pm 0.04 *(-17.04)$ \\
\hline 2. & Liver & $0.97 \pm 0.09$ & $0.83 \pm 0.068^{*}(-14.43)$ & $1.76 \pm 0.12^{* *}(-31.25)$ \\
\hline 3. & Brain & $2.82 \pm 0.25$ & $2.42 \pm 0.08^{*}(-14.32)$ & $2.14 \pm 0.051^{*}(-20.62)$ \\
\hline 4. & Muscle & &
\end{tabular}

Values are the mean of $(\mathrm{n}=5) \pm \mathrm{SD} *=P<0.05 ; * *=P<0.01 ; * * *=P<0.001$ 


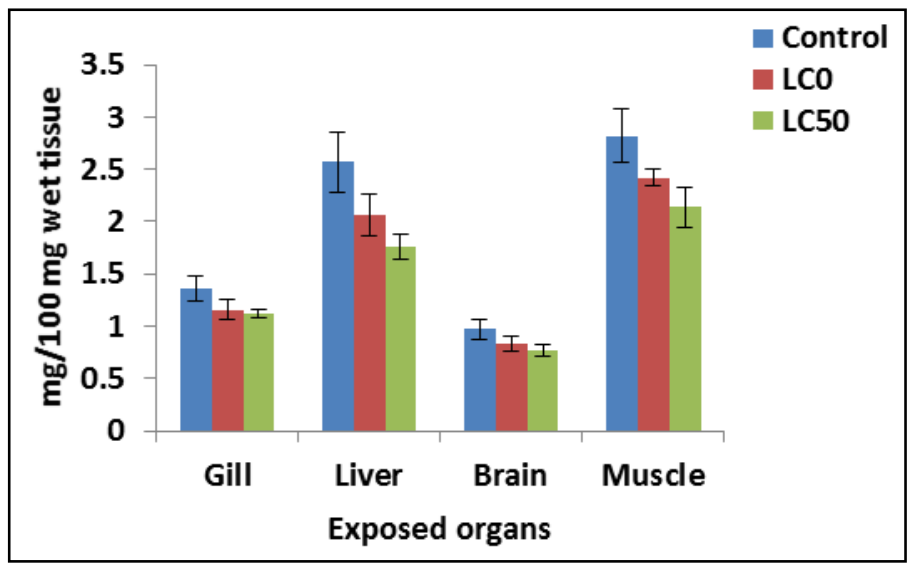

Fig 1: Effect on the total lipid content of freshwater fish Cirrhinus mrigala after acute exposure to Methanol.

\section{Discussion}

Biochemical alterations deal with the chemistry of the growth and activity of living organisms. It is a chemistry where most reactions are controlled by complex proteins called enzymes and are moderated and limited by hormones. The chemistry is always highly complex and is still not fully understood. Decomposition of organic material is also within the scope of biochemistry although in this case it is the growth and activity of fungi, bacteria and other micro-organisms that is involved. Typical types of change include all the process involved in photosynthesis, a process in which carbon dioxide and water are changed into sugars and oxygen by plants, digestion in which energy rich materials are used by organisms to grow and move, Krebs cycle which liberates energy from stored reserves, protein synthesis which enable organisms to grow using processes controlled by RNA etc. Biochemical alterations are referred as bioindicator for monitoring the pathological and physiological status of fish (Baskaran 1991) ${ }^{[2]}$. Any alterations in biochemical parameters represent the response of organ systems to toxicants by changing their function (Verma and Tonk, 1983) ${ }^{[9]}$.

\section{Lipid}

A lipid is a substance of biological origin that is soluble in nonpolar solvents. It comprises a group of naturally occurring molecules that include fats, waxes, sterols, fat-soluble vitamins, monoglycerides, diglycerides, triglycerides, and phospholipids. The main biological functions of lipids include storing energy, signaling, and acting as structural components of cell membranes. Lipids have applications in the cosmetic and food industries as well as in nanotechnology. Scientists sometimes broadly define lipids as hydrophobic or amphiphilic small molecules; the amphiphilic nature of some lipids allows them to form structures such as vesicles, multilamellar/unilamellar liposome's, or membranes in an aqueous environment. Biological lipids originate entirely or in part from two distinct types of biochemical subunits or "building-blocks": ketoacyl and isoprene groups. Using this approach, lipids may be divided into eight categories: fatty acids, glycerolipids, glycerophospholipids, sphingolipids, saccharolipids, and polyketides; and sterol lipids and phenol lipids. Lipids are one of the major sources of energy forerunner under any stressful condition. Lipids are the group of fat soluble compounds found in the tissues of plants and animals. It includes fats, phospholipids, sphingomyelins, waxes and sterols. It is the vital organic substance, playing an important role in energy metabolism. The toxicity stress suppresses the activity of a number of enzymes responsible for lipid transformation ultimately causing disturbances in lipid metabolism.

A significant decrease $(P<0.05)$ in the levels of total lipid content were observed when Cirrhinus mrigala exposed to varying concentrations of methanol for 4 and 30 days. Similar findings made by Rajee Olaganathan and Jamila Patterson (2013) ${ }^{[5]}$ observed a significant decrease in lipid content in fish Channa punctatus and Cyprinus carpio on exposure to anthraquinone dyes for 30days. Olaganathan and Patterson (2013) ${ }^{[5]}$ studied the effect of Anthraquinone dyes on the lipid content in the muscle of Channa punctatus and reported increase in lipid contents during $7^{\text {th }}$ day with decrease on $18^{\text {th }}$ and $30^{\text {th }}$ day exposure. In the present investigation, stress imposed by lethal and sub lethal exposure of the Methanol to Cirrhinus mrigala resulted in a marked decrease in lipid content, there by indicating high-energy demand. This observation confirmed that due to the diseased condition and the coupled effect of toxicant and microbes, all the three major metabolites like protein, lipid and glycogen got depleted drastically from the tissue Olaganathan and Patterson (2013) ${ }^{[5]}$. Lipid is used as energy reservoir, stored and transported in the form of glycerol ester. Lipid plays an important role in energy metabolism and provides energy to metabolic processes. The decrease level in lipid content in tissues suggested that the lipid have been channelized to meet the metabolic demand for extra energy needed to mitigated the toxic stress reported by Shruti et al., (2014) ${ }^{[7]}$. Reduction in lipid content observed in present study might be due to utilization of lipids for energy demand under stress condition. The decrease in lipid content was cited by Binukumari S and R Sudhasaravanan (2015) ${ }^{[3]}$ who noticed decrease in lipid content caused due to general damage and blockage of enzyme system for steroidogenesis. Marked alterations in lipid metabolism have been reported in acute and chronic exposure of methanol. Decline in the lipid content was due to the utilization of lipids for meeting the energy demand under the toxicant stress (Somaiah et al., 2015) ${ }^{[8]}$. The decrease in lipid content in the tissue was due to cope with stress induced energy demand Sangeetha and Rani (2016) ${ }^{[6]}$. Similar result observed by History et al., (2018) ${ }^{[4]}$ in muscle, liver, brain and kidney tissues of fish Catla catla exposure to heavy metal ferrous sulphate.

\section{Summary and Conclusion}

In acute toxicity experiments the freshwater fish Cirrhinus mrigala were exposed to organic solvent Methanol which showed that experimental fish was sensitive to Methanol. In the present study, the $96 \mathrm{hr} \mathrm{LC}_{50}$ value of Methanol to was observed to be $12,250 \mathrm{mg} / \mathrm{L}$ with $95 \%$ confidence limit ranging between 14,230 to $11,270 \mathrm{mg} / \mathrm{L}$. On acute exposure to Methanol, fishes showed erratic swimming, restlessness and jerky movements of body.

The total lipid content was decreased in fishes exposed to both the acute concentrations of Methanol, but this decrease was more significant in $\mathrm{LC}_{50}$ group than $\mathrm{LC}_{0}$. After chronic exposure, lipid level was considerably decreased in both the chronic concentrations of Methanol as compared to control. The decrease in lipid content might be due to high energy demand in order to get positive survival value under toxic stress or may be caused due to general damage and blockage of enzyme system for steroidogenesis. 


\section{References}

1. Barnes H, Blackstock J. Estimation of Lipids in Marine Animals and Tissues: Detailed Investigation of The Sulpho Phospho Vanillin method for 'Total' Lipids." J. Exp. Mar. Biol. Ecol 1973;12:103-118.

2. Baskaran P. Use of Biochemical Parameters on Biomonitoring of Pesticide Pollution in some Freshwater Fishes. Ecotoxicol. Environ. Monit 1991;1(2):104-109.

3. Binukumari S, Priyadarsini V, Vasanthi J. Impact of Diclofenac Drug on the Biochemical Composition of the Fresh Water Fish, Cirrhinus Mrigala. Int. J. Adv. Res. Biol. Sci. International Journal of Advanced Research in Biological Sciences www.ijarbs.com 2016;3(3):153-59.

4. History P, Ilavazhahan M, Tamilselvi RL. Biochemical Alteration in The muscle, Liver, Kidney and Brain of a Fresh Water Fish, Catla catla (Ham.) Exposure of a Heavy Metal Toxicant Ferrous Sulphate 2018, 5.

5. Olaganathan R, Patterson J. Effect of Anthraquinone Dyes on the Carbohydrate, Protein and Lipid Content in the Muscle of Channa punctatus. International Journal of Pharmaceutical Applications 2013;4:11-18.

6. Sangeetha S, Deepa Rani S. Histological and Biochemical Changes Caused by the Pesticides Endosulfan, Chlorpyrifos and Carbaryl on the Gonads of Fiddler Crab , Uca triangularis. World Journal of Environmental Pollution 2016;6(1):7-14.

7. Shruti S, Tantarpale VT. Effects of Cypermethrin on Lipid and Cholesterol Contents of Freshwater Fish Channa orientalis. Paripex- Indian Journal of Research 2014;3(8):200-201.

8. Somaiah Karra, Satish PVV, Sunita K, Baratha Jyothi N. Studies on the Biochemical Responses in the Tissues of Freshwater Fish Labeo rohita exposed to the Organophosphate, Phenthoate. Int. J. Pharm. Sci. Rev. Res 2015;32(20):108-115.

9. Verma SR, Sarita Rani, Tonk IP, Dalela RC. PesticideInduced Dysfunction in Carbohydrate Metabolism in three Freshwater fishes. Environ. Res 1983;32:127-133. 